RHS Revista Humanismo

RT y Sociedad

\title{
Una reflexión sobre las cadenas productivas ${ }^{\perp}$
}

\author{
A reflection on the productive chains
}

Jesús Alfredo Berdugo Gutiérrez ${ }^{1^{*}}, \mathrm{MV}$, MSc.

${ }^{1}$ Docente-investigador. MSc en Genética Humana de la Universidad Nacional de Colombia.

(Aceptado: 9 de diciembre de 2014)

\section{Introducción}

Desde que se creó la ley 811 del 2003 donde se definió la formación de las cadenas productivas el MADR se dio a la tarea de apoyar el establecimiento de las mismas, con la convicción que ese modelo de integración de los interesados pudiera ser la solución para el desarrollo del campo colombiano, entendiendo que ese sistema es la respuesta al proceso de industrialización de la producción de alimentos para los seres humanos.

"Originalmente, la palabra cadena se ha utilizado para referirse a un objeto constituido por una serie de eslabones, generalmente metálicos, enlazados entre sí". La cadena de la que hablamos los eslabones son personas naturales o jurídicas que intervienen directa $\mathrm{o}$ indirectamente en el producción de alimento. Es fundamental entender que la cadena y sus eslabones son un todo, lo que afecta al primero tiene que afectar al último, eso debe impulsar un gran sentido de la solidaridad y la corresponsabilidad para que sea exitosa. La cadena es tan larga como mayor valor se le vaya a adicionar al producto, esto el resultado de las tendencias mundiales que han aparecido en los países desarrollados: la agregación de valor a los productos y la participación de los consumidores dentro de estos procesos. Se puede tomar como ejemplo, el caso de la carne de bovino, el precio de un novillo en pie en la finca (potrero báscula) a diciembre del 2014 estaba en un rango entre 2800 y 3200 pesos, y el precio de un plato de carne asada (punta de anca, 300 gr) en un restaurante de cinco estrellas esta por el orden de los 40.000 pesos, pero adicionalmente ya aparecen consumidores piden cortes especiales o animales de una u otra calidad pues tienen la necesidad o el gusto de nutrirse, no necesariamente comprar lo que pueden para satisfacer una necesidad primaria.

Lo anterior es una exposición muy corta sobre la motivación de hacer cadenas, es un sueño en el que cada uno de los eslabones tuviera su parte dentro del negocio y así de ser posible entre todos llegar al final, dentro o fuera del país. Nos referiremos en este documento a la cadena cárnica bovina.

${ }^{\perp}$ Para citar este artículo: Berdugo Gutiérrez, JA. Una reflexión sobre las cadenas productivas. RHS. Revista. Humanismo. Soc, Volumen 2 (2): 65-69.

*Autor para correspondencia: Jesús Alfredo Berdugo Gutiérrez. Correo electrónico: jesusberdugo64@gmail.com. 


\section{Los eslabones de la cadena}

Es complicado poder identificar cuantos eslabones tiene la cadena, especialmente por la diversidad de sistemas productivos, pero uno puede hacer una cadena sencilla de tres, productores, comercializadores y transformadores. Gobierno y proveedores de estos tres eslabones estarían involucrados en forma de ramificaciones, que facilitan el proceso pero que no son parte directa de él.

Intentemos mencionar los eslabones tiene la cadena:

1. Productor: tenemos claro que la carne, se produce en sistemas productivos donde se tienen animales que consumen alimento y lo convierten en carne, eso significa que en la finca se venden animales vivos. Independiente de como lo hace.

2. Comercializador: no siempre quién produce le interesa comercializar, apare ce aquel comercializador, que no le da valor agregado al producto, pero facilita que el producto salga llegue a los grandes centros de conumo que llamaremos frigorífico o feria.

En la feria, hay otros comercializadores que venden a personas que van a vender el producto en los expendios para ser consumidos en la casa y/o mayoristas de carne para cosumo en casa (grandes superficies) y para transformación.

3. Transformador: el animal tiene la obligación de convertirse en alimento, para ello se necesitan dos condiciones:

- Debe ser llevado a un frigorífico o una planta de faenado.

- Debe ser comprado por un transformador, que hace que el animal, se convierta en proteína animal.

En el frigorífico vuelve y repite lo mencionado en la feria, pues los que sacrifican venden su carne a minoristas de tienda (con diferentes grados de tecnificación), y otros que venden la carne para ser servida en otros negocios que llamaremos como un conjunto restaurantes (donde cada uno de la valor agregado, dependiendo sus preparaciones y condiciones comerciales), otro segmento grande se va para aquellos transformadores que hacen subproductos o embutidos y un cuarto potencial cliente aquellos que quieren hacer negocios con esa carne buscando mercados nacionales e internacionales con sus diferentes nichos de mercada e interés.

Este primer transformador, tiene una característica especial que vende carne y sus derivados, además que necesita del frigorífico para ejercer su labor (los frigoríficos en el país, rara vez ellos compran la carne) y es afectado por las normas sanitarias del ICA y las de Invima, de modo que él responde o le toca afrontar problemas de situaciones que nunca vio, conoció y más grave aún, le importaron.

Así las cosas nuestra cadena tiene tres eslabones fundamentales (pareciera tan fácil) pero la realidad es que tiene tantas apéndices como nuestra cultura y diversidad.

\section{La realidad de la cadena}

Desde mi punto de vista, aquellas cadenas que se considera funcionan por que van desde el productor a la mesa, como la avícola y alguna parte de la porcícola, no lo son, por que los eslabones pertenecen la misma empresa, finalidad y organización. Considero en lo operativo, que no es lo mismo conocer todos los eslabones y manejarlos, que articular diferentes personas o empresas para lograr el mismo objetivo.

Así las cosas, con un trabajo de años, veo con preocupación que la realidad de las cadenas dista mucho del objetivo planteado. En mi andar por el país me he hecho la siguiente pregunta: será que a un productor en la sierra de la macarena le interesará mucho si el señor que pide un plato de carne asada en un restaurante de Bogotá, le sabe a bueno?, debería, pero la respuesta es NO. La gran pregunta es ¿por qué no?

Voy a proponer algunas respuestas, alrededor de las cuales giran muchas de las acciones de la cadena:

\section{El productor le gusta que le paguen su producto} potrero báscula, normalmente al mejor postor, después de eso el no quiere saber nada diferente a que le sea pagado. Muchas de las veces sin ni siquiera conocer si su ejercicio financiero fue o no rentable. Se tiene aún muy fresco el fenómeno Venezuela, 
cuando de la noche a la mañana pasaron los mismos animales de valer 2600 pesos $/ \mathrm{kg}$ a 4500 pesos, repito los mismos.

2. El productor no quiere asumir riesgos, ni si quiera el básico del transporte, ahora menos el de los controles sanitarios, el prefiere darle cabida a un actor que podemos llamar el comercializador que haga ese trabajo y asuma ese riesgo. Puede ser comprensible, en algunas ocasiones los animales que van a ser consumidos en nuestro país tienen largas jornadas de a pie o en lancha, antes de subirse a un camión, que generalmente tiene jornadas de 8 a 12 horas antes de llegar a los centros de consumo. Esto hace que la diferencia de peso entre la báscula de finca y la llegada a la planta de faenado sea a veces hasta del 15\%, lo que en un novillo sea $400 \mathrm{~kg}$, sea de $60 \mathrm{~kg}$ que puede representar fácilmente entre cuatro $\mathrm{y}$ cinco meses de ceba.

\section{El productor se resigna con lo que produce y no} quiere que nadie lo sea. Dadas las condiciones en que se trabaja se produce como se puede en medioambientes no se controlan, así que su producción depende de sequias o inundaciones, de abundancia de forrajes o escases, de forma que estandarizar para darle gusto al consumidor se puede convertir en una tarea titánica por no decir imposible. Adicionalmente no quiere que las ventas sean facturadas, ni tributar por sus ganancias o descontar sus pérdidas.

\section{Muchas personas que engordan ganado no son} precisamente productores. Dada la idiosincrasia de nuestro negocio, la ganadería en el país es la forma más fácil y económica de ocupar/aprovechar la tierra entonces nuestro productor no lo es tanto logra con animales hacer una adecuada posesión de la tierra y eso es muy importante. El gran punto aquí es que se generan obligatoriamente dos negocios, el de la tierra y el del ganado, eso es algo malo para la producción ganadera. En lo social una persona puede manejar 500 novillos, que fácilmente pueden estar en una extensión de igual número de hectáreas, ¿cuántas personas pueden ocuparse en $500 \mathrm{Ha}$ de cultivos?

De esta manera, tenemos un productor que solo quiere su plata por el producto, por lo cual le da paso a lo que llamamos el comercializador, un actor que en nuestro caso se vuelve importante, no por darle valor agregado al producto, sino por ayudar a solucionar el gran problema del productor.

Los intermediarios al no ponerle valor agregado al producto, se convierten en unos actores con otras funciones pues su papel se convierte en solucionar el problema del criador, el asume riesgos y a veces se convierte en proveedor de servicios financieros, pero el lucha en la mitad de la cadena, entonces trata de sacarle al productor su producto lo más barato posible (facilita esto que el productor normalmente no sabe cuánto le cuesta) y vendérselo lo más caro al que transforma (que a veces no le importa mucho pues los sobreprecios se los transfiere al que sigue en la cadena), es como muchos ven en este ejercicio una gran oportunidad pues su trabajo se dedica a conseguir a quien venderle en los centros y a responder por el valor de los animales.

El transformador, difícilmente está a gusto con el producto que se ofrece. Para la transformación se deben tener en cuenta algunos aspectos pues el que transforma el animal en alimento para los seres humanos debe tratar con algunos actores adicionales:

El frigorífico, en nuestro país los frigoríficos no son parte del negocio, son en la mayoría de los casos sitios donde se presta un servicio, bien sea sacrificó de animales o recauda un impuesto o la fuente de materia prima para un subproducto. Ellos no son cadena, están en un negocio y tienen que propender por subsistir, el único punto es que en sus instalaciones realizan los controles que ha establecido el gobierno para esta transformación, acciones que por su naturaleza enrarecen a veces el mercado.

Tenemos varios transformadores:

El que vende la carne en el barrio que su única forma de darle valor agregado al producto es diferenciándolo mediante una mejor atención al cliente, y que las fluctuaciones del precio del producto no le afetan por que se la transfiere a su cliente (acá sale la famosa frase : "la carne nunca baja de precio").

El que compra carne para transformarla en forma de alimento servido en un plato. Ellos quieren calidad, y eventualmente están dispuestos a pagar por ello. En la evolución de los mercados esto ha marcado un aspecto sobre lo que se ha trabajado, la trazabilidad. En este 
grupo pueden considerarse las grandes superficies, dentro de la responsabilidad que a ellos compete por el hecho de ser los mayores proveedores de alimentos para la población.

Los que compran la carne como insumo inicial para transformación, bien sea para embutidos o para entregarla al consumidor final en forma de platos en un restaurante. Estos consumidores, son los que más necesitan la calidad del producto, entendida por sus características organolépticas (aspecto, sabor, textura) como la logística del mismo, son frecuentes las preguntas de como asegurar que siempre haya $\mathrm{y}$ del mismo, que pueda uno entrar en la cultura de la planeación, que su precio se ajuste a los valores de un menú, que si bien es cierto lleva nuestro producto también tiene muchos otros elementos que favorecen el valor agregado.

Los que han encontrado en la carne una gran oportunidad de negocio, basado en la globalización, La búsqueda de nuevos mercados que tiende a solucionar el problema de la gran demanda mundial de alimentos, estos potenciales eslabones también se quejan, pues fuera del país las normas la pone no solo el cliente sino los gobiernos, el mercado y las políticas que muchas veces son ajenas al mismo productor o comercializador.

\section{Papel de los entes de control}

Queda claro que en la cadena productiva el gobierno y los entes de control, son algunas de las apéndices mencionadas, no tienen un lugar definido, cada uno solo sabe qué hacer, pero ¿cuál es su puesto en la cadena? $\mathrm{Si}$ se mira este ejemplo: se requiere un producto para consumir en un restaurante gourmet que exige que provenga la carne de un hato libre de tuberculosis: ¿al productor quién los vigila? El ICA lo certifica como libre, y el ganadero envía su animal a la central de faeno, allí llega y de la puerta para adentro quién define las normas es el Invima, el inspector recibe el animal, que esta aparentemente sano y autoriza su sacrificio y en el faenado se encuentra con unos nódulos, compatibles con tuberculosis y lo decomisa. Cada organismo sabe que hacer, sin embargo.

Surgen las siguientes preguntas:

¿Quién debe perder el dinero del animal decomisado?
¿Qué responsabilidad le cabe al ICA, cuando se certifica un "predio" pero no los animales? Un ganadero está libre de una enfermedad, pero realmente está libre de qué?

¿El Invima es consciente de su papel en la cadena? ¿Cuál es el tipo de retroalimentación?

Para agravar el panorama todo lo anterior se da en un espacio lejos de los interesados, en un frigorífico.

Se considera que la calidad, como valor agregado es fundamental, y que por ahora quién impone la calidad es el gobierno a través del ICA e Invima directamente sobre productores y producto, el único comentario es que su accionar se ha convertido en algo policivo más que en el favorecimiento de una cultura.

Tres puntos fundamentales del problema son:

¿Qué hacer para que el productor se interese?

¿Qué hacer para que el intermediario le de valor agregado al producto?

¿Qué hacer para que el transformador tenga la materia prima en la cantidad y la calidad necesaria para su operación?

Se considera fundamental que se establezca cual sea el valor de la intermediación cuanto debe ganar este actor? En la práctica puede verse que lo que gana un cebador en cuatro o cinco meses, se lo gana este señor en una semana o menos.

Finalmente, se tiene radiografía de la cadena, tres eslabones donde el primero (productor) y el último (transformador) ni se conocen, ni les importa hacerlo pues ambos tienen necesidades diferentes sobre el mismo producto y un eslabón intermediario sobre el cual se ejercen muchas presiones, pero que tampoco le interesa mucho lo que pase pues el sabe que mientras el ser humano consuma y le guste la proteína animal de origen bovino tendrá un negocio asegurado.

\section{Acciones a llevar a cabo}

¿Qué hacer? Desde mi punto de vista estos años han servido para que al menos haya una sensibilización sobre el problema, es claro que hay que tener una cadena 
pero no puede ser de uno solo, pues eso reconoce las diferentes etapas del proceso.

Quedan unas grandes preguntas:

¿A quién le toca organizar la cadena? Por ahora la respuesta seria el estado (MADR), pero es claro que la norma dice es que al estado le toca favorecer la formación no hacerla, así las cosas ¿será de un particular o de una persona jurídica que se llame un gremio o una asociación?.

¿Quién puede poner valores a la intermediación?, ¿cuál es el margen de utilidad de un servicio? Por ejemplo, se puede calcular con mucha exactitud la diferencia en el precio para el pago potrero báscula o en la feria, pero ¿cuánto debo ganarme por asumir el riesgo de traerlo, la disminución y la variación entre la oferta y la demanda?.

¿Cómo hacer para que los frigoríficos no sean actores pasivos?

¿Cuánto cuesta darle valor agregado a un producto?

\section{Propuestas}

Propuesta general. Educar a los eslabones, sobre el concepto de cadena
Propuestas particulares. Propiciar espacios de discusión entre los entes encargados del control, para buscar formas de armonizar en la cadena, que nunca se nos debe olvidar que es un negocio. En el primer caso este Instituto depende directamente del MADR y en el segundo depende del MPS.

Mi propuesta, es arrancar por hacer cultura, educar, llegar a que las personas se conozcan y entiendan su papel, pero todos juntos. Hacer que el discurso sobre calidad, inocuidad, trazabilidad, seguridad alimentaria sea una vivencia para todos los eslabones de la cadena.

Dado el tamaño de los búfalos, la gran propuesta es hacer una cadena con valoración de todos los aspectos del mismo e intentar hacerla funcionar. Si cada uno de los actores de la cadena esta cómodo, se podrá concentrar en su actividad misional, de esta forma el productor podrá ser productor y atender los requerimientos del transformador que es en últimas su cliente.

Unos eslabones bien remunerados y tranquilos en la cadena podrán charlar con los otros actores indirectos de la cadena como lo son el gobierno, en todos sus aspectos las medidas sanitarias, de inocuidad y comercio exterior y los entes financiadores de los diferentes aspectos del negocio 